\title{
Using Locative Media to Enrich Spaces with Historical Artifacts
}

\author{
Aidan Power
}

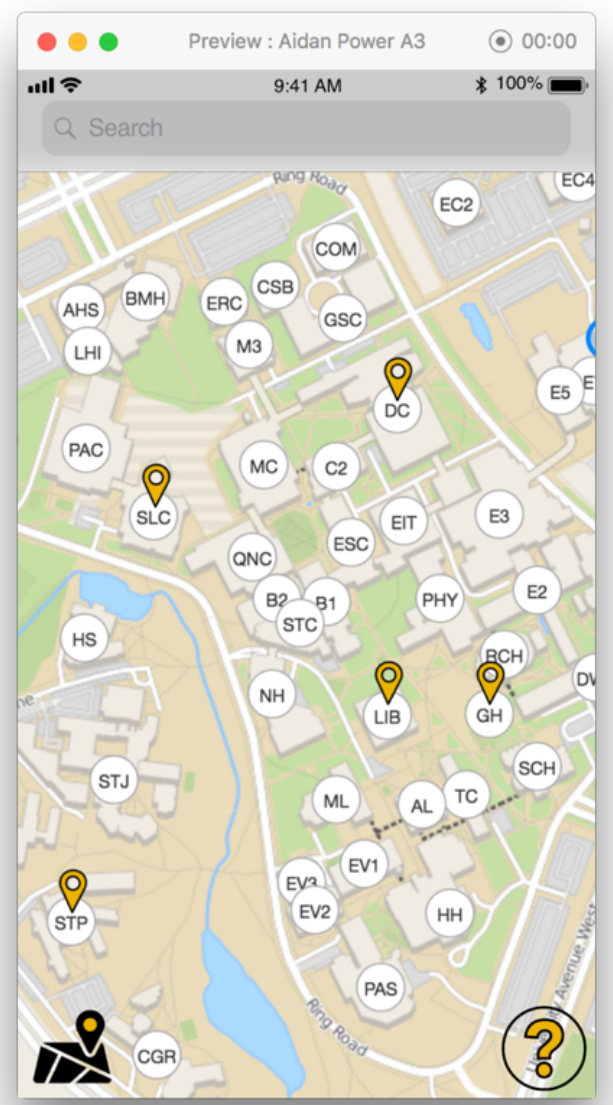

When users first open the app, they are presented with a map of the various locations on campus that contain AR artifacts. Upon arriving at each location they can click on the markers that will allow them to "scan" the space for AR artifacts and display them over top of the existing scenes. 

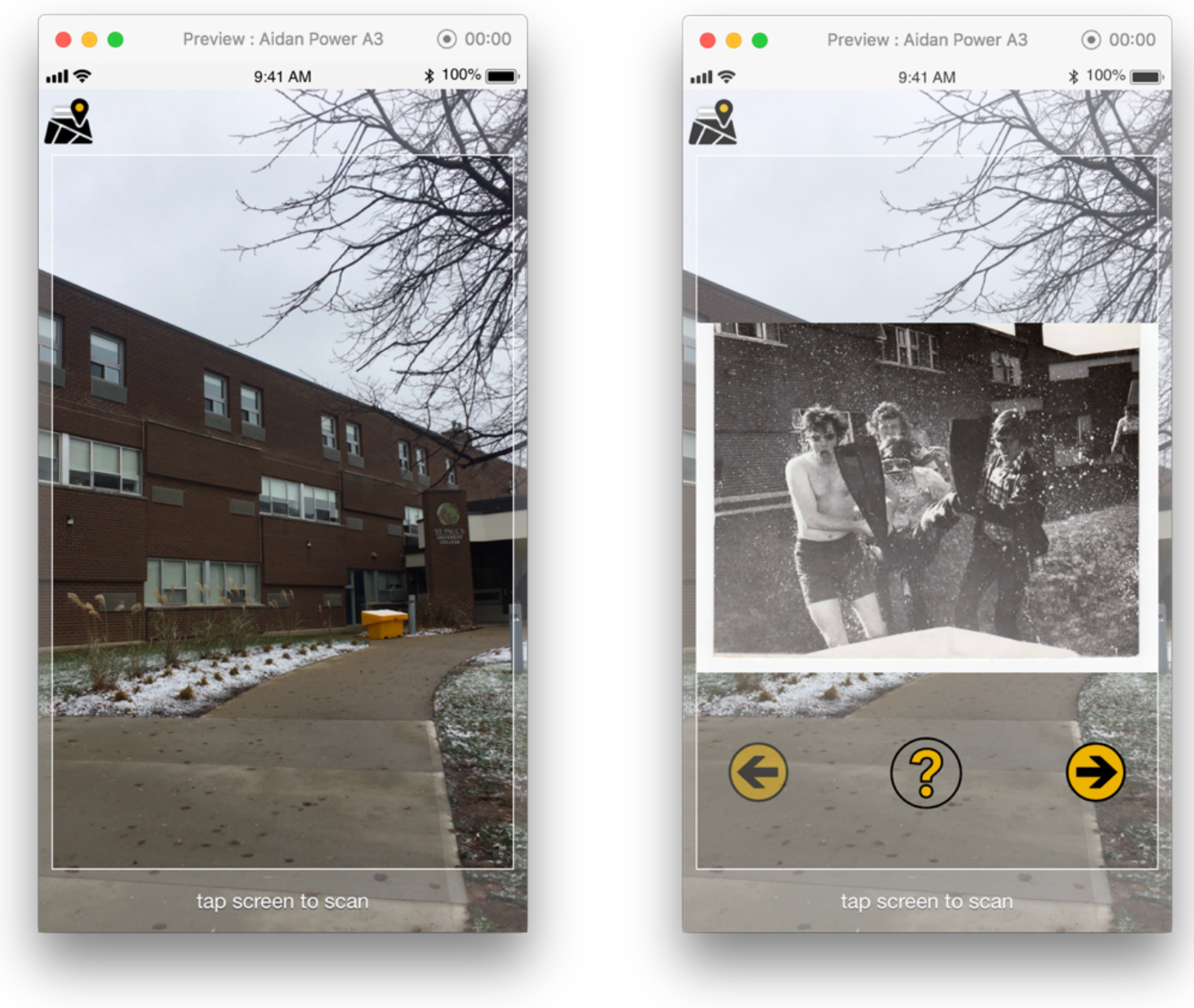

At St. Paul's University College, users can see images from residence orientations gone by, such as this photo from the mid 1960's where students go diving in an outdoor pool! 

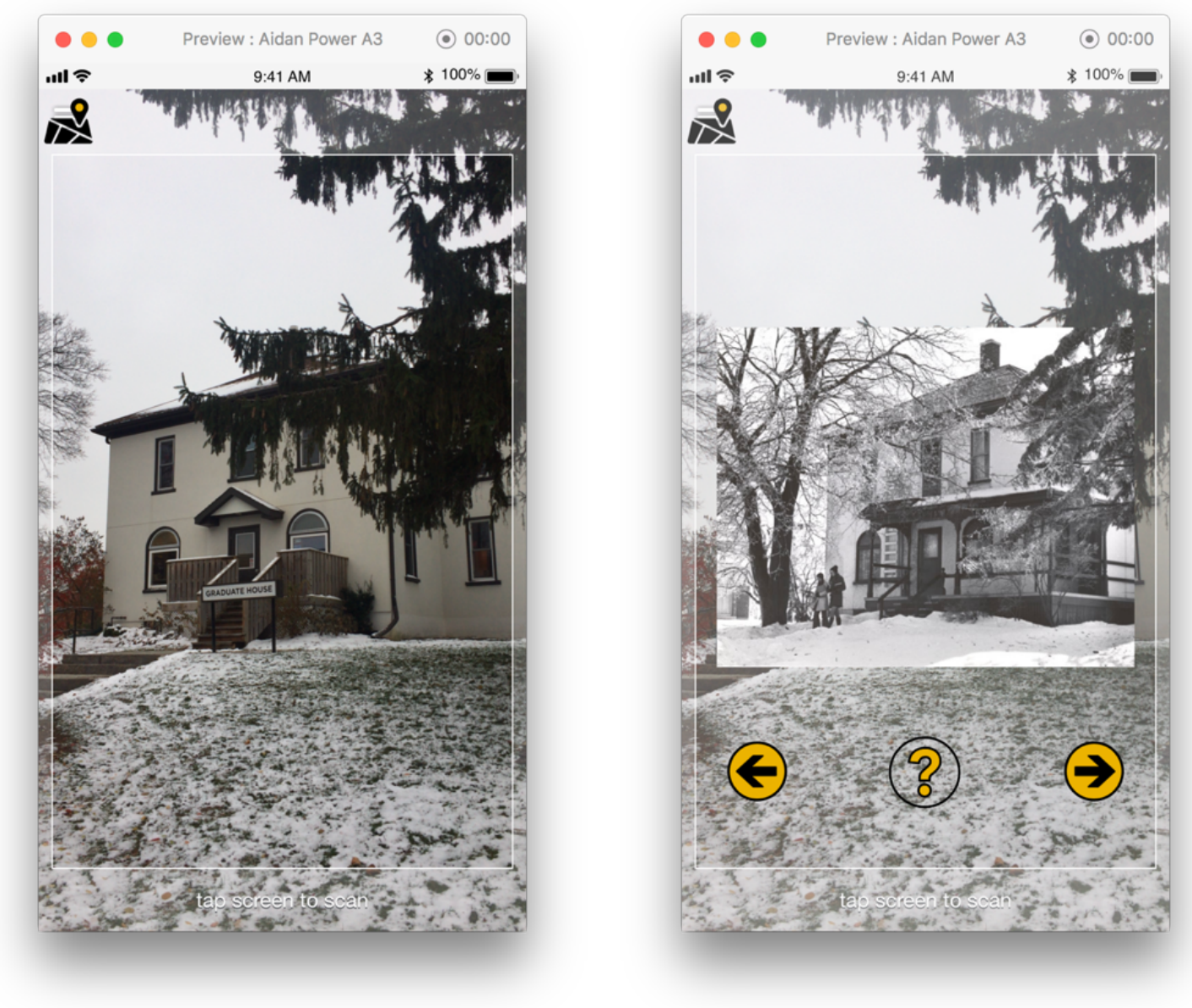

The Graduate House was originally named the Schweitzer Farmhouse as it was where the farmers lived before their land was purchased by the University of Waterloo in the 1950s. The AR artifact here shows the Grad House in the middle of winter in the 1970s. 

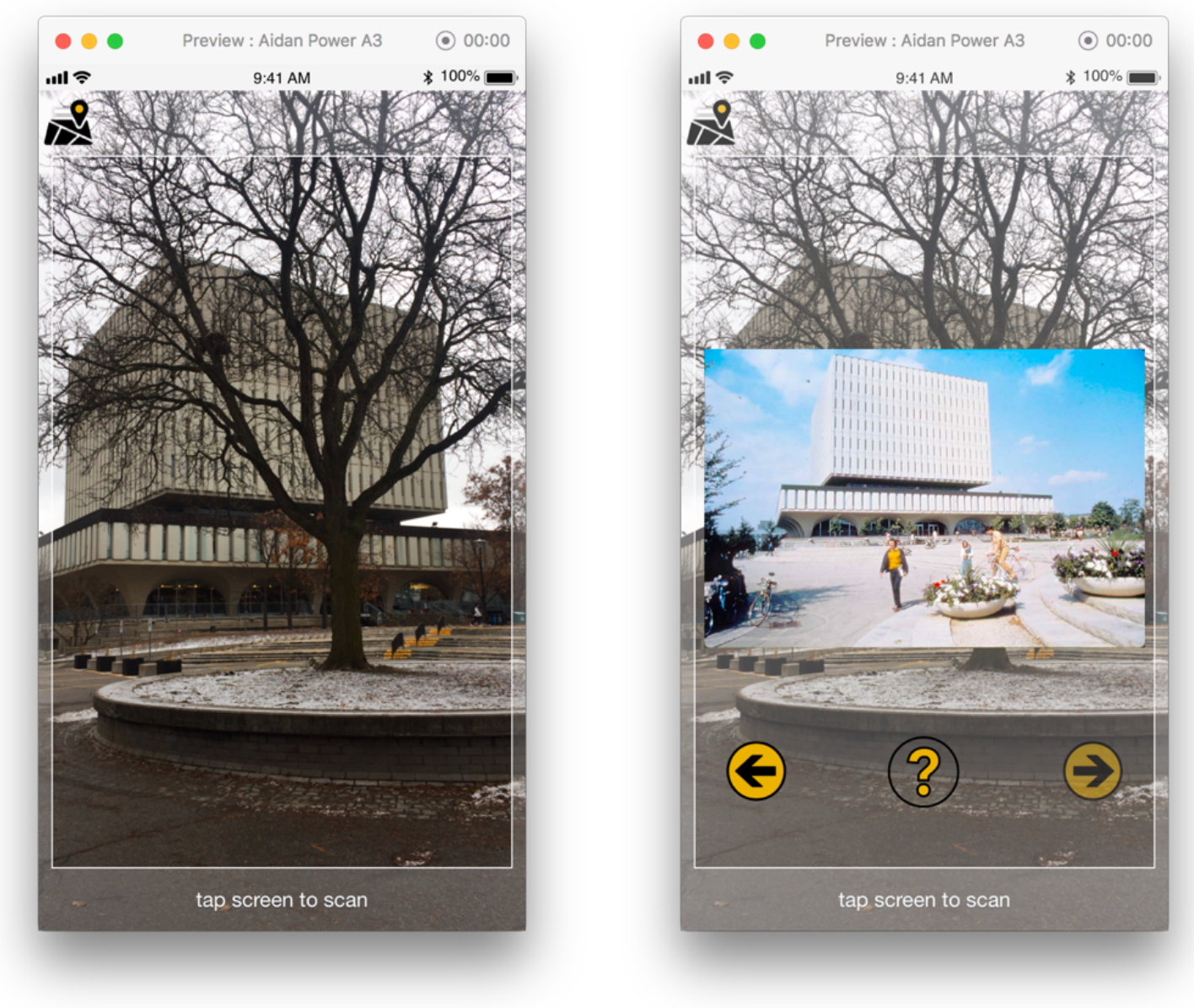

Dana Porter Library, originally constructed to be 7 stories tall, had an additional 3 stories added to it in the early 1970 s. 

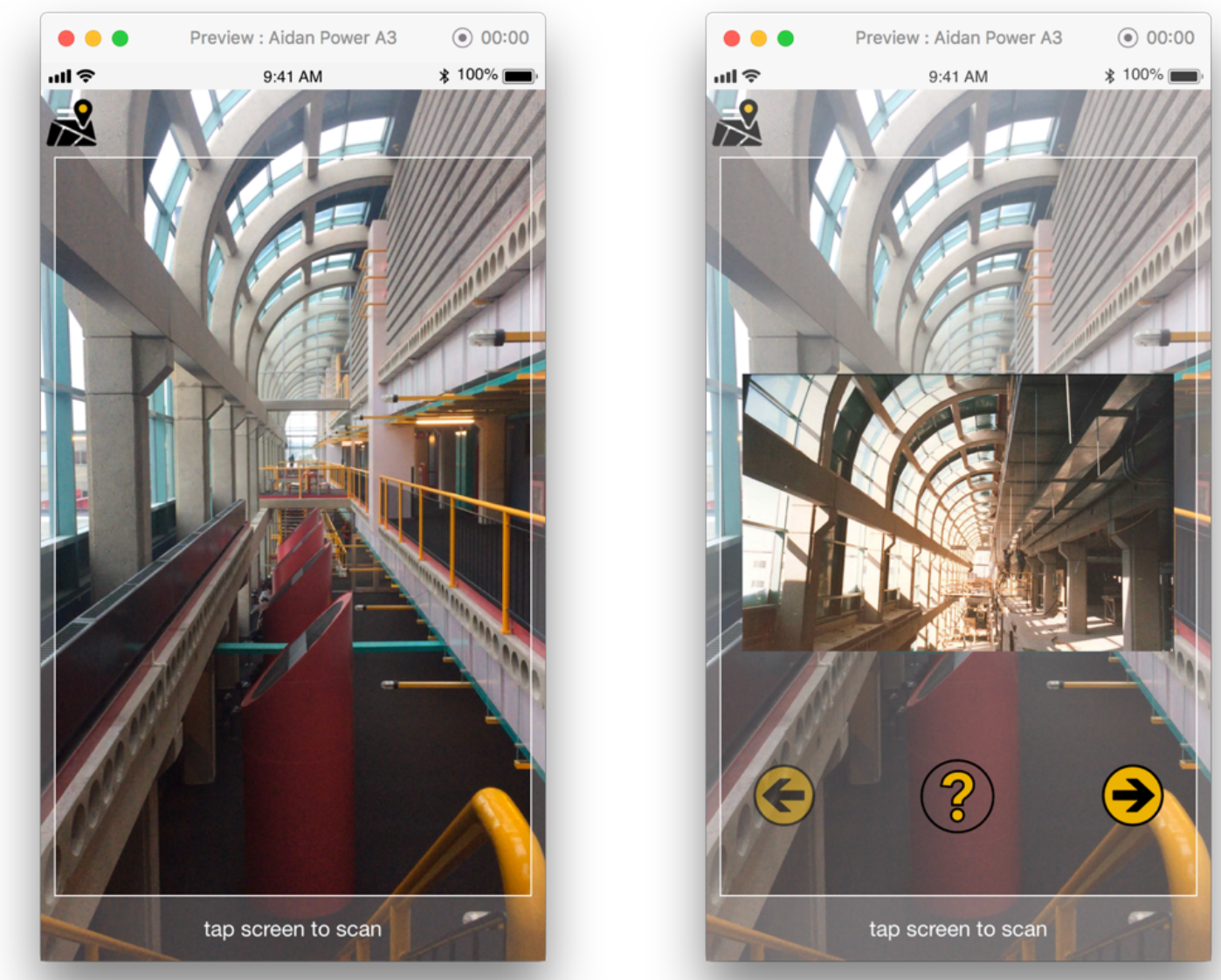

At the William G. Davis Computer Research Centre when it was constructed between 1985 and 1988. 

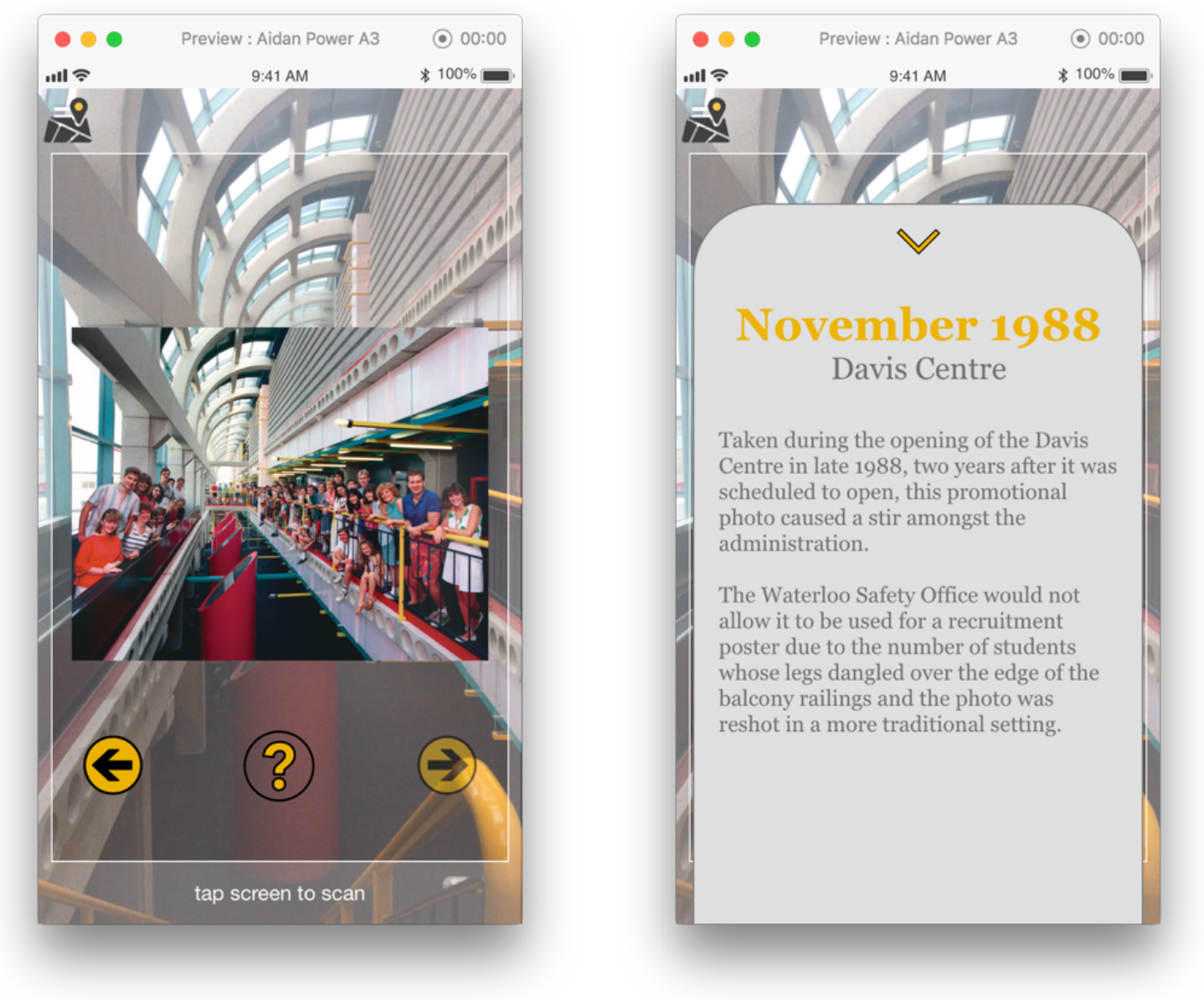

By swiping up on the question mark, users can read interesting stories about each AR artifact, as well as when and where it was taken. This story dives into a promotional shot from the opening of the Davis Centre in 1988. 
N FINE 229: Hybrid Digital Media, I created 1 a prototype of a mobile augmented reality application that allows students and visitors on the University of Waterloo campus to explore the space through rich historical photos and accounts. The app is meant to be used by students at the University of Waterloo as a way of connecting them to the institution's past, the students who have come before them and their lived experiences. It achieves this by overlapping the familiar, contemporary landscapes with historical photos that create a liminal space between the past and present.

Augmented Reality (AR) can be described as the "integration of digital information with the user's environment in real time" (Rouse, 2015). Simple examples of AR include Google Maps, which responds to users' movements in space in real time, while more complex examples often use a mobile screen as a camera to display the built environment around the user with digital media artifacts laid over top.

This project makes use of mobile technology and augmented reality to examine how space can be reinvented over time through the camera and location settings on one's smartphone. It brings together interface design, locative media studies, and history to produce new experiences for users and expose them to forgotten or rarely remembered stories. Swiping up on an image, users can read about the story behind it, as well as when and where it was taken.

The app is meant to be accessible on the go for students to enter a space, "scan" it, and be exposed to the rich history it has to offer, from demonstrations in the SLC to the construction of some of the most recognizable buildings on campus. I drew inspiration from the Mi Querido Barrio Augmented Reality Exhibition commissioned by the Caribbean Cultural Center African Diaspora Institute (CCCADI) in New York City, which used the Blippar AR app. Mi Querido Barrio used AR to showcase forgotten or lost street murals in East Harlem, similarly to how this project presents archival photos of Waterloo in front of their present day sites through one's camera phone.

This project brings together a wide variety of resources including images from the $60^{\text {th }}$ Anniversary Image Bank, put together by the University's Special Collections \& Archives and image banks put together by faculties and residences across campus. Each photo's description is based on writings from Water Under the Bridge, a collection of stories about campus over the years by Chris Redmond, who worked on campus as an editor of the Gazette and later the Daily Bulletin.

\section{AUTHOR BIOGRAPHY}

I am an undergraduate student at the University of Waterloo majoring in Knowledge Integration, with a Computer Science minor and a Science, Technology and Society specialization. Augmented Reality is a very fascinating story telling device and this project allowed me to bring together my interests in user experience design, history and artistic practice. It was inspired in part by a need for a stronger sense of community within the university institution, where historical moments are often forgotten within 4-5 years as the student body graduates. Leveraging augmented reality technology, I hope that a project similar to this one could inspire students to connect with the rich and diverse past that the University of Waterloo has to offer. I would like to thank JIRR for their support and for creating a platform where undergraduate students can share their writings on important, interdisciplinary topics. 


\section{Works Cited}

Abdulrahem, Noma, Nicole Bennett, Layrissa Li, University Press. "Waterloo, Then and Now" waterloo.ca. University of Waterloo, March 14th, 2017.

https://uwaterloo.ca/innovation60/blog/post/waterloo-then-and-now

Loo, Stephen. "Historic Timeline" uwaterloo.ca/stpauls/. St. Paul's University College, 2013. https://uwaterloo.ca/stpauls/celebrating-50-years/historic-timeline

Redmond, Chris, Simon the Troll. "Water Under the Bridge" uwaterloo.ca. University of Waterloo. https://uwaterloo.ca/water-under-the-bridge/

Rouse, Margret. "Augmented Reality (AR)" whatis.techtarget.com. What is.com Tech Target, 2015. https://whatis.techtarget.com/definition/augmented-reality-AR

"Mi Querido Barrio Augmented Reality Exhibition and Tour" cccadi.org. Caribbean Cultural Center African Diaspora Institute, 2013, 2016. https://www.cccadi.org/miqueridobarrio

"Historical Photos" uwaterloo.ca/math/. The Faculty of Mathematics. https://uwaterloo.ca/math/ historical-photos 